\title{
MAPEAMENTO AEROGAMAESPECTROMÉTRICO DA ALTERAÇÃO HIDROTERMAL ASSOCIADA À MINERALIZAÇÃO NO DISTRITO FLUORÍTICO DE SANTA CATARINA, BRASIL
}

\author{
Rosemary Hoff ${ }^{1}$, Silvia Beatriz Alves Rolim² e Artur Cezar Bastos Neto ${ }^{3}$ \\ Recebido em 26 março, 2004 / Aceito em 20 agosto, 2004 \\ Received March 26, 2004 / Accepted August 20, 2004
}

\begin{abstract}
The geophysical data processing (airborne gamma ray spectrometry) supplied the results in granites affected for the hidrotermal alteration in the Santa Catarina Fluorine District. The facies zonation in granites is associated to the granitic magmatism suggesting the rock fluor source. This lead to understanding the regional distribution of the fluorine deposits and defined new criteria for the prospecting of fluorine, space relations for the mineralization and the rock fluor source. This study shows that this source is situated in external portions of the Pedras Grandes Massif.
\end{abstract}

Keywords: fluorine, hydrothermal alteration, gammaspectrometric mapping.

RESUMO. 0 processamento de dados geofísicos (aerogamaespectrométricos) forneceu resultados em granitos afetados pela alteração hidrotermal no Distrito Fluorítico de Santa Catarina. A zonação faciológica em granitos está associada ao magmatismo granítico sugerindo a rocha fonte de flúor. Isto conduziu ao entendimento da distribuição regional dos depósitos de fluorita e definiu novos critérios para a prospecção de fluorita, as relações espaciais para a mineralização e a rocha fonte de flúor. Este estudo mostra que esta fonte está situada no fácies externo do Maciço Pedras Grandes.

Palavras-chave: fluorita, alteração hidrotermal, mapeamento aerogamaespectrométrico.

\footnotetext{
${ }^{1}$ CPRM - Serviço Geológico do Brasil, Rua Banco da Província, 105 - CEP: 90840-030 Porto Alegre, RS, Brasil - Tel: (55 51) 3233-7311, Fax: (55 51) 3233-7772 - E-mail: rosehoff@pa.cprm.gov.br

2Departamento de Geodésia, Instituto de Geociências - UFRGS, Av. Bento Gonçalves, 9500, 43136, 108 - CEP: 91501-970 Porto Alegre, RS, Brasil Tel: (55 51) 3316-6352, Fax: (55 51) 3316-6340 - E-mail: silvia.rolim@ufrgs.br

${ }^{3}$ Departamento de Mineralogia e Petrologia, Instituto de Geociências - UFRGS, Av. Bento Gonçalves, 9500, 43126, 101 - CEP: 91501-970 Porto Alegre, RS, Brasil Tel: (55 51) 3316-6358, Fax: (55 51) 3316-6340 - E-mail: artur.bastos@ufrgs.br
} 


\section{INTRODUÇÃo}

0 Distrito Fluorítico de Santa Catarina (DFSC) é o maior produtor de fluorita da América do Sul. Cerca de 3 Mt (ROM com teor médio de $40 \%$ de CaF2) foram produzidas em 40 anos de exploração contínua, cujo auge (300.000 t/ano) aconteceu na década de 80. Na última década, a pesquisa por novos depósitos estagnou, mas a produção nacional permaneceu concentrada no DFSC, onde as reservas atuais são de apenas cerca de $2 \mathrm{Mt}$ (minério in situ com 50\% de CaF2). Assim, diante de uma necessidade de demanda de mercado por novas áreas, a pesquisa vem sendo retomada.

0 DFSC ocorre numa faixa de $100 \mathrm{~km}$ de comprimento por 60 km de largura, delimitada a oeste pela Bacia do Paraná e a leste pelo Oceano Atlântico (Figura 1). 0 embasamento faz parte do Cinturão Dom Feliciano (Fragoso César, 1980), onde predominam os granitos Pedras Grandes e Tabuleiro (Sallet, 1988; Morgenthal \& Kirchner, 1983). Zanini et al. (1997) e Silva \& Leites (2000) classificaram os mesmos granitos dentro da Suíte Pedras Grandes e identificaram ocorrências de Granito Santo Antônio. Os granitóides são cortados por diques de rochas subvulcânicas ácidas E0-cambrianas (Teixeira, 1969). As rochas da Bacia do Paraná presentes no distrito pertencem às formações Rio do Sul (folhelhos e diamictitos) e Rio Bonito (arenitos, siltitos e carvão), ambas do Permiano Inferior. Estes sedimentos são cortados por diques e soleiras de diabásio da Formação Serra Geral (JuroCretácea). Na parte norte do distrito ocorre a intrusão alcalina de Anitápolis.

Produtos do processamento de dados de aerogamaespectrometria têm sido bastante utilizados na identificação e delimitação de corpos graníticos. Sua aplicação no DFSC conduziu à subdivisão da área em três domínios: D1, D2 e D3, bem como à determinação de zonas de alteração hidrotermal associadas a intrusões graníticas (Rolim, 2001). Seu uso ainda permitiu a delimitação do Maciço Pedras Grandes e sua zonação em relação à alteração hidrotermal.

\section{MÉTODOS}

Os dados aerogeofísicos utilizados foram cedidos pela Companhia de Pesquisa e Recursos Minerais (CPRM) - Serviço Geológico do Brasil - CPRM, relativos ao Projeto Serra do Mar Sul (CPRM, 1994), levantamento de 1978 efetuado pela GEOFOTO S.A. As medidas gamaespectrométricas foram registradas de 60 em 60 metros ao longo de linhas de vôo na direção N $30^{\circ} \mathrm{W}$, espaçadas em 1000 metros e altura de vôo de 150 metros.

As etapas de aquisição, compilação e correção dos dados geofísicos foram realizadas pela empresa executora do levantamento, juntamente com a CPRM (CPRM, 1994). Os processamentos para este trabalho foram realizados no programa GEOSOFT 4.2 (GEOSOFT, 1997).

Neste trabalho, adotou-se 0 valor da célula das malhas de $250 \mathrm{~m}$, de acordo com o valor estabelecido pela freqüência de Nyquist, que preserva as freqüências menores ou iguais à metade da frequiência de amostragem entre as linhas de vôo. As malhas regulares foram geradas pelo algoritmo de interpolação de curvatura mínima, calculado a partir do padrão de amostragem do aerolevantamento para evitar os efeitos de falseamento.

0 micronivelamento foi realizado com base em Minty (1991), aplicando-se métodos de filtragem direcional, ao longo e perpendicular às linhas de vôo, com a finalidade de remover erros residuais não associados à informação geofísica.

Os resultados foram obtidos pela interpretação de mapas de contagem total, Urânio (U), Tório (Th), Potássio (K) e Fator F (Efimov, 1975). Este último avalia o comportamento do K em relação à razão $\mathrm{Th} / \mathrm{U}$, podendo estar associado à presença de processos de alteração hidrotermal com enriquecimento secundário em K.

\section{RESULTADOS \\ Contagem Total}

A Figura 2 apresenta o mapa de contagem total, mostrando que a área do embasamento do DFSC pode ser dividida em três domínios radiométricos. 0 Domínio 1 (D1) é caracterizado por anomalias radiométricas de intensidade média e está associado ao Granitóide Santa Rosa de Lima, unidade geológica mais antiga da área. 0 Domínio 2 (D2) constitui uma zona central de maior intensidade e uma zona periférica de intensidade média a alta, apresentando uma contribuição radiométrica dos Granitóides Santo Antônio e Imaruí-Capivari. 0 Domínio 3 (D3) corresponde aos sedimentos quaternários da planície costeira, predominando baixas intensidades radiométricas na área estudada.

\section{Canais Urânio, Tório e Potássio}

0 mapa de urânio (Figura 3) mostra uma distribuição espacial das unidades radiométricas semelhante à da contagem total, com 0 D2 apresentando uma área central com alta intensidade de $\mathrm{U}$, e uma zona periférica de menor intensidade. No D1 são relativamente mais freqüentes ocorrências pontuais de alta intensidade.

0 mapa de tório (Figura 4) mostra no D2 uma redução na largura da zona central de alta intensidade, que passa a configurar-se como uma faixa de direção NE-SW. 


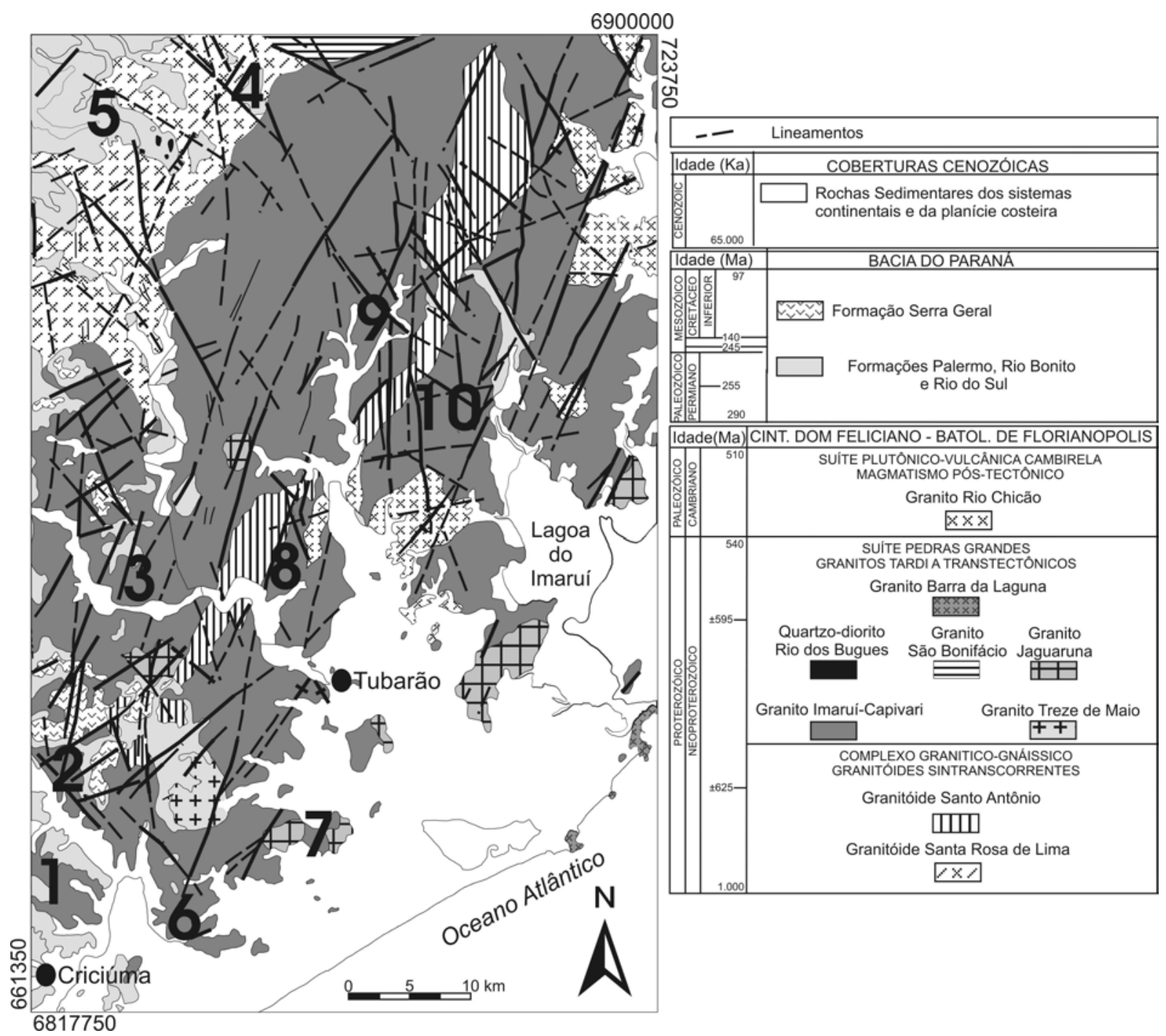

Figura 1 - Mapa Geológico Regional (modificado de Silva \& Leites, 2000). Ocorrências de fluorita nos subdistritos: 1 - Segunda Linha Torrens; 2 - Ribeirão da Areia; 3 - Pedras Grandes; 4 - Rio Bravo Alto; 5 - Grão-Pará e nos filões: 6 - Garganta; 7 - Jaguaruna; 8 - São Martinho; 9 - Armazém; 10 - São Tomás.

Figure 1 - Regional Geologic Map (modified of Silva \& Leites, 2000). Fluorine occurrences in sub-districts: 1 - Segunda Linha Torrens; 2 - Ribeirão da Areia; 3 Pedras Grandes; 4-Rio Bravo Alto; 5 - Grão-Pará and filons: 6-Garganta; 7-Jaguaruna; 8 - São Martinho; 9 -Armazém; 10 - São Tomás.

0 mapa de potássio (Figura 5) mostra no D2 uma área de maior intensidade e mais extensa do que nos mapas de urânio e tório. Não se configura uma zona periférica bem definida e a área de maior intensidade extrapola os limites externos das áreas periféricas dos mapas de U e Th.

\section{Fator $F$}

0 Fator F mostra a distribuição do Potássio em relação aos elementos Urânio e Tório. 0 Fator $F$ se baseia na operação entre os dados de urânio, tório e potássio por meio da seguinte expressão:

$$
F=K . U / T h .
$$

$\mathrm{Na}$ imagem do Fator $\mathrm{F}$ (Figura 6) observa-se que a distribuição das unidades radiométricas é muito condicionada ao comportamento do potássio, em relação à distribuição de urânio e tório. No D2, a área de maior Fator $F$ corresponde a uma ampliação dos limites da área de maior intensidade do potássio (Figura 5), para sudeste, dentro dos maciços adjacentes à planície costeira, onde os picos de alta intensidade são bem mais abundantes. 


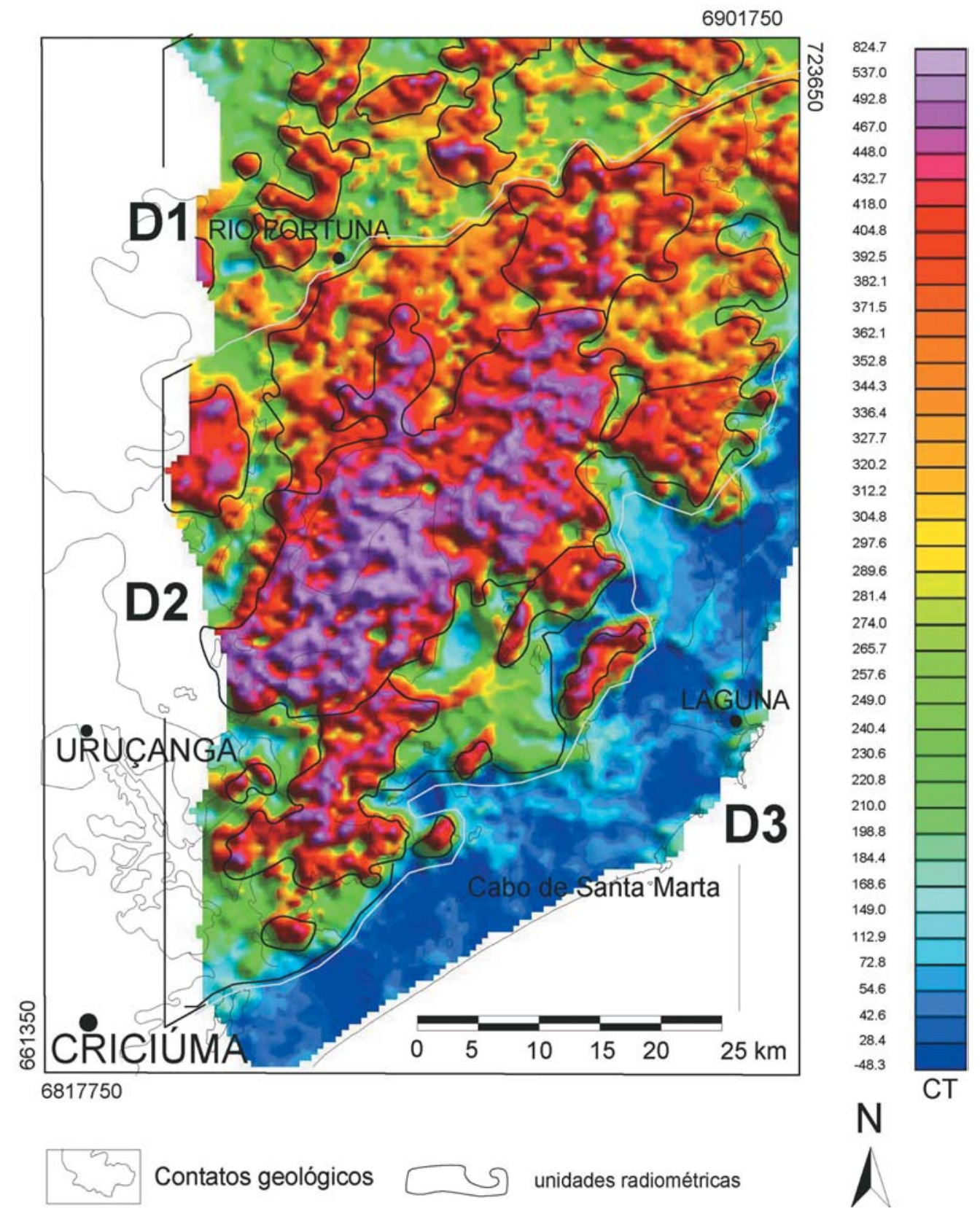

Figura 2 - Imagem radiométrica - contagem total.

Figure 2 - Radiometric image - total count.

\section{DISCUSSÕES}

\section{Arcabouço Geológico do DFSC: o Maciço Pedras Grandes}

0 domínio sul é caracterizado na imagem radiométrica de contagem total (Figura 2) por uma área central de maior intensidade, alongada na direção NE-SW, circundada por uma zona periférica de intensidade média. A área central é essencialmente constituída pelo Granito Imaruí-Capivari, conforme Silva \& Leites (2000). A zona periférica é constituída predominantemente pelo mesmo granito, associada a sudeste com ocorrências do Granito Jaguaruna e, em menor proporção, por rochas subvulcânicas (Granito Rio Chicão). Por outro lado, constata-se que as novas ocorrências de corpos do Granito Jaguaruna, identificadas mais a oeste, se dispõem perifericamente à zona de maior intensidade 


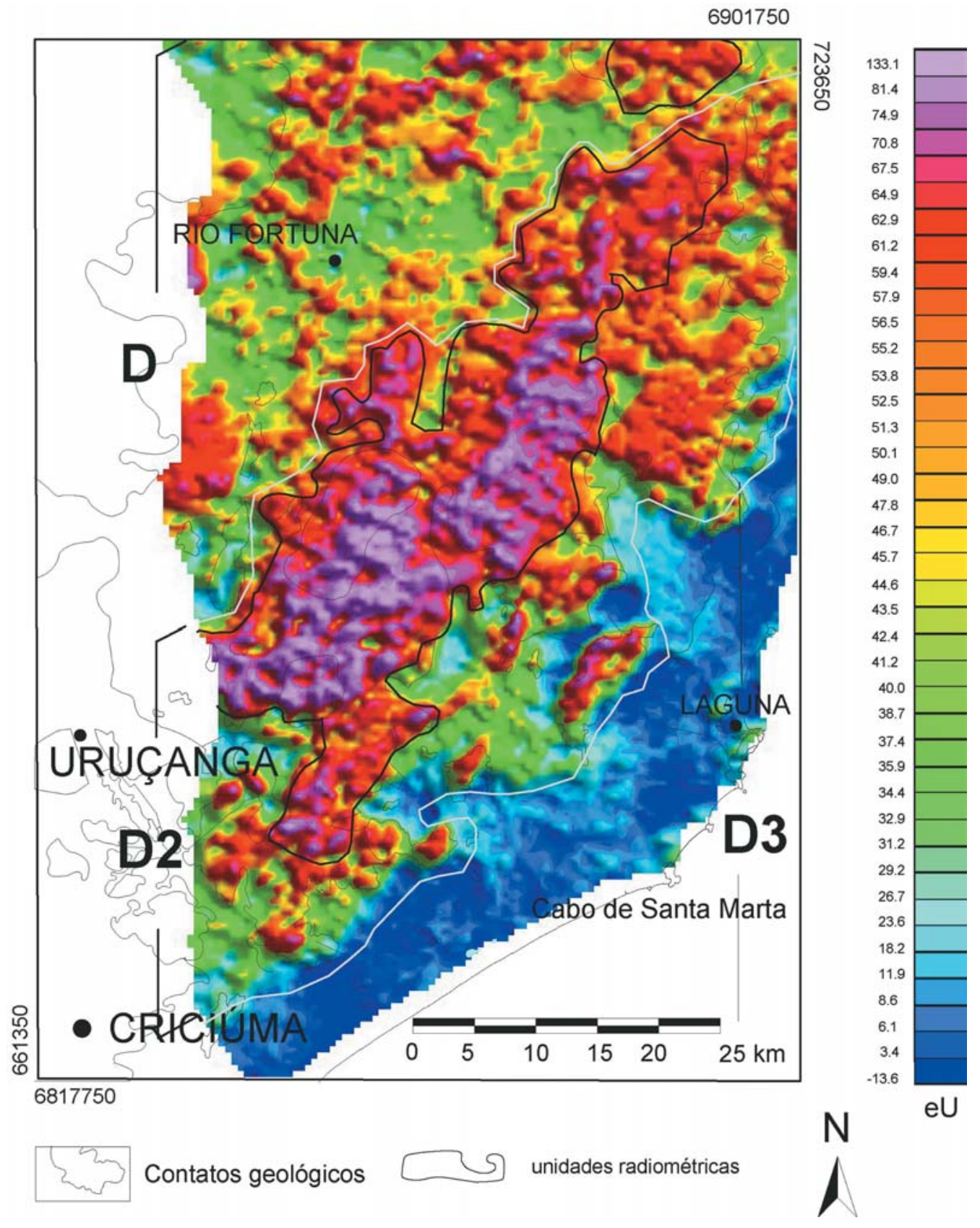

Figura 3 - Imagem radiométrica - Canal urânio.

Figure 3 - Radiometric image - Uranium channel.

radiométrica. Configura-se uma zonação regional do ora denominado Maciço Pedras Grandes, com uma distribuição de fácies mais finas no entorno de uma área central constituída por rochas de granulação mais grosseira.

Nesta interpretação, as rochas subvulcânicas que ocorrem localizadamente em partes mais centrais do maciço (Granito Treze de Maio e alguns corpos do Granito Rio Chicão) poderiam corresponder a fácies apicais da intrusão granítica. Nas imagens radiométricas dos canais urânio e tório (Figuras 3 e 4, respectivamente) as zonas centrais de maior intensidade apresentam uma excelente correlação e poderiam corresponder ao núcleo do maciço, onde estes dois elementos teriam sido menos remobiliza- 


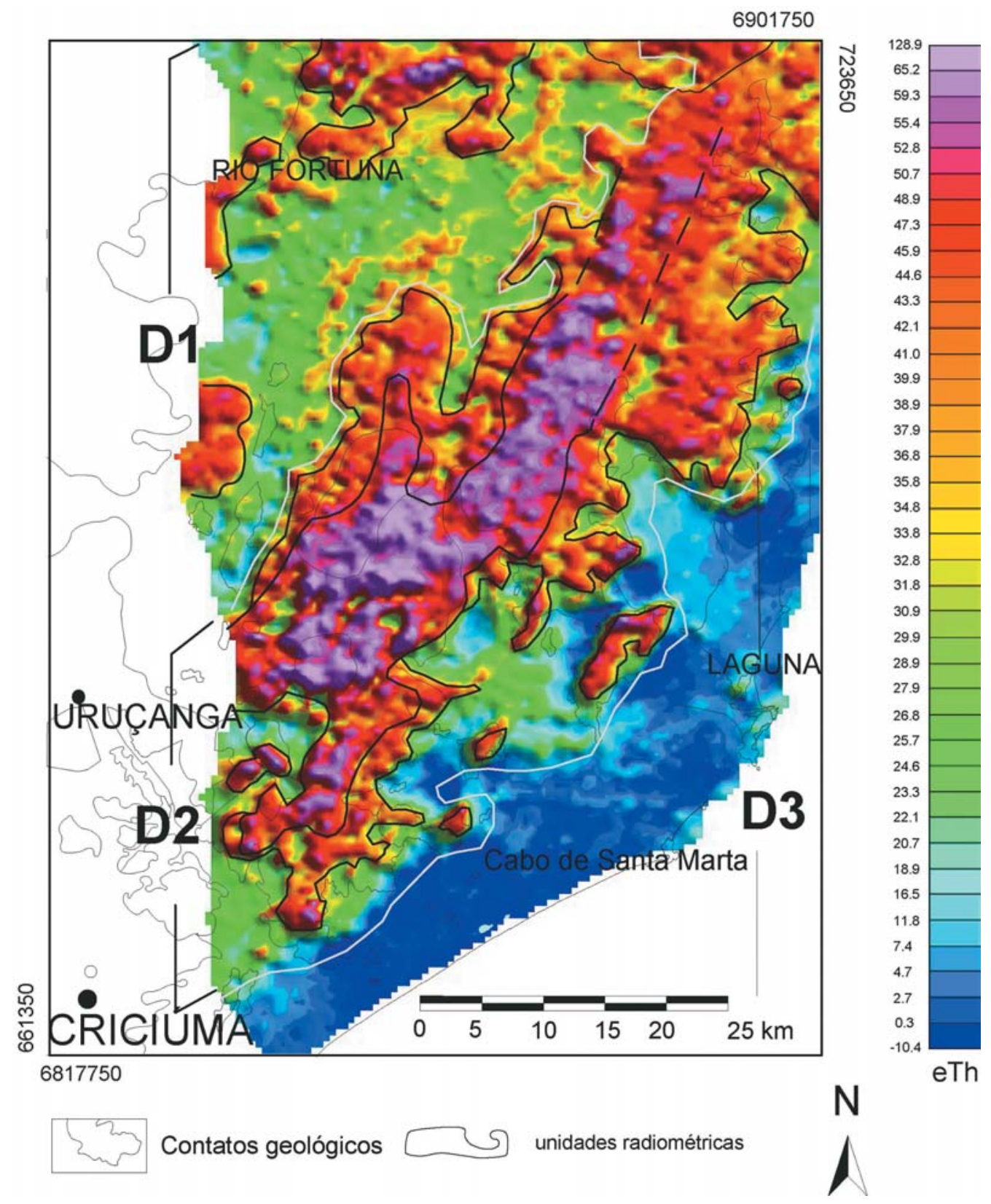

Figura 4 - Imagem radiométrica - Canal Tório.

Figure 4 - Radiometric image - Thorium channel.

dos por processos de alteração mais freqüentes e efetivos nas bordas de um corpo ígneo intrusivo. A porção nordeste do domínio sul (Figura 3) não pertenceria ao Maciço Pedras Grandes. Entretanto, segundo consta em todos os mapas disponíveis, esta parte da área é constituída por rochas correlacionadas ao Granito Pedras Grandes ou suas variações. Segundo Hoff (2002), esta porção da área também apresentou comportamento anômalo em imagens orbitais processadas, que revelaram a presença de uma quantidade excepcional de óxidos de ferro interpretados como relacionados a uma abundância de diques de diabásio. No interior do domínio 2 (Figura 2), observa-se um alinhamento N-S de maior intensidade que se superpõe à extremidade norte da faixa constituída pelo Granito Santo Antônio. Entretanto, os dados radiométricos indicam que esta faixa não se prolonga para SSW 


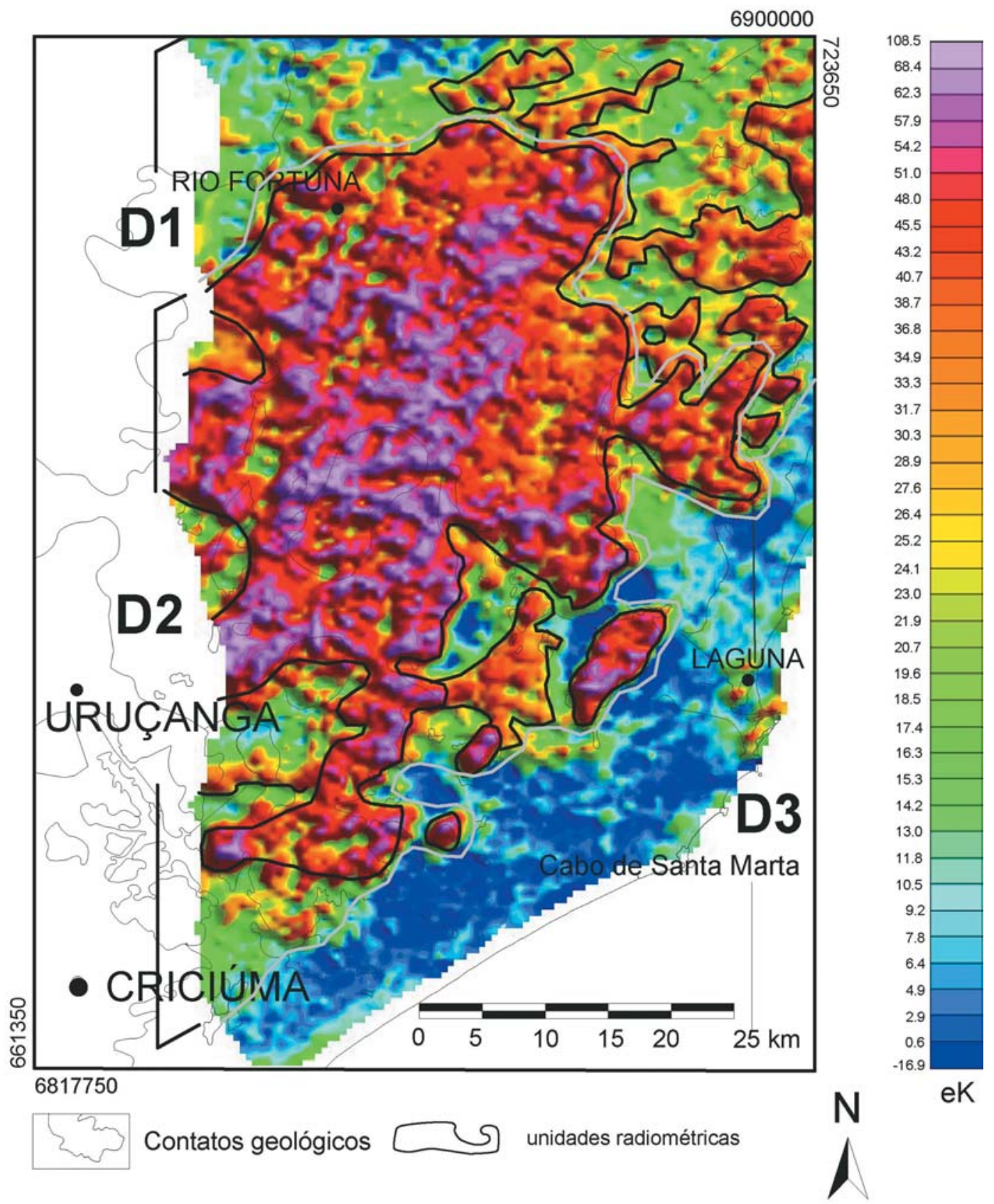

Figura 5 - Imagem radiométrica - Canal Potássio.

Figure $\mathbf{5}$ - Radiometric image - Potassium channel.

além do limites da Área II. Para norte, esta faixa é aparentemente interrompida pelo sistema de lineamentos ENE-WSW que separa os domínios norte e sul.

Para 0 domínio 1, os dados gamaespectrométricos indicam a existência de uma associação de rochas claramente dis- tinta do domínio 3. As intensidades média e baixa predominantes no domínio norte nos canais urânio e tório são mais bem atribuídas a rochas metamórficas, podendo pertencer à Faixa Granito-Gnáissica Santa Rosa de Lima/Tijucas - FSRL. 0 prolongamento desta faixa pela borda oeste do domínio sul é apa- 


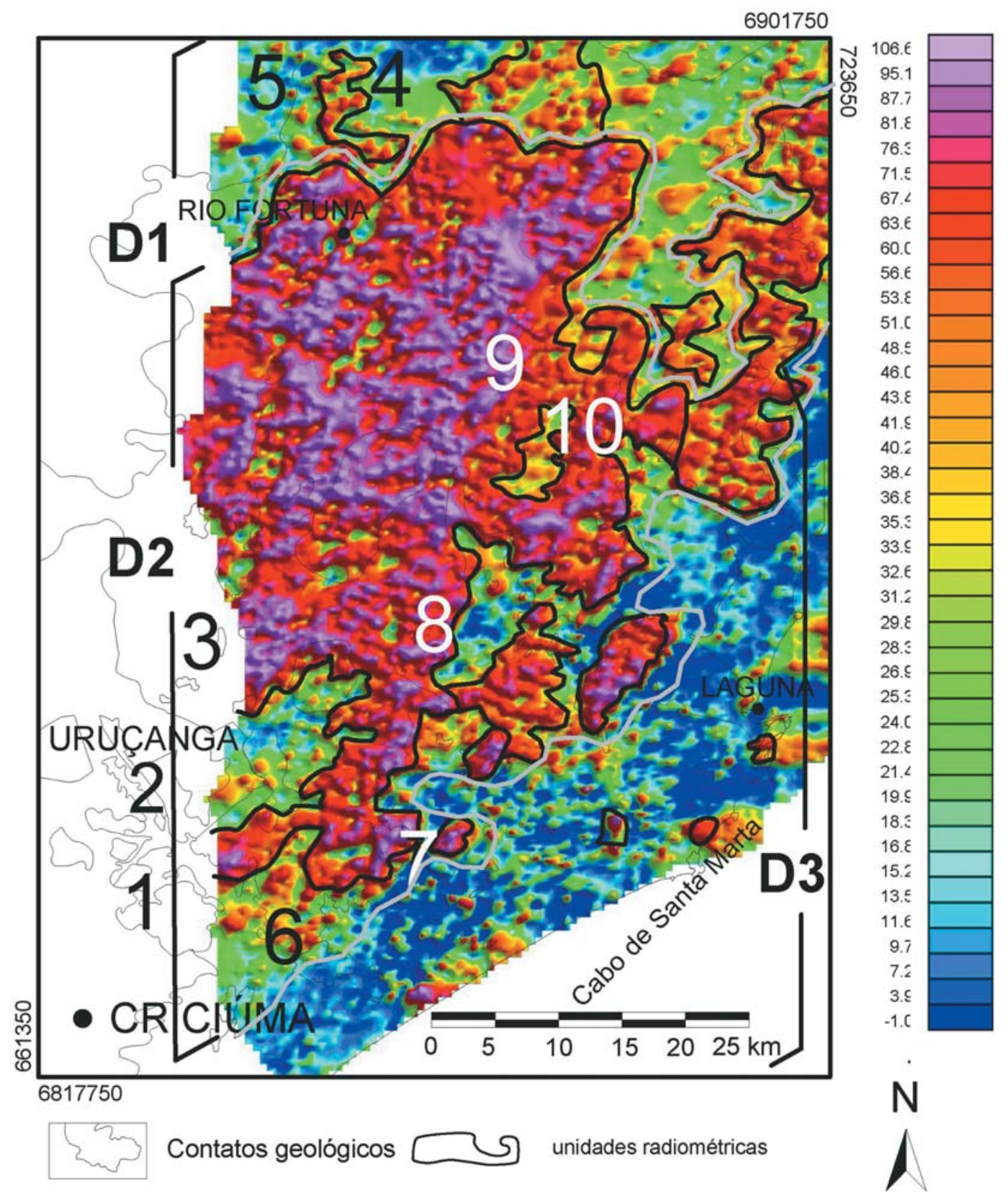

Figura 6 - Imagem radiométrica - fator F. Ocorrências de fluorita nos subdistritos: 1 - Segunda Linha Torrens; 2 - Ribeirão da Areia; 3 - Pedras Grandes; 4 - Rio Bravo Alto; 5 - Grão-Pará e nos filões: 6 - Garganta; 7 - Jaguaruna; 8 - São Martinho; 9 - Armazém; 10 - São Tomás.

Figure 6 - Radiometric image - factor F. Fluorine occurrences in sub-districts: 1 - Segunda Linha Torrens; 2 - Ribeirão da Areia; 3 - Pedras Grandes; 4 - Rio Bravo Alto; 5 - Grão-Pará and filons: 6-Garganta; 7-Jaguaruna; 8 - São Martinho; 9 -Armazém; 10 - São Tomás.

rentemente bem mais restrito do que observaram Silva \& Leites (2000) Por outro lado, os dados radiométricos indicam que estas rochas não se restringem a uma faixa NNE-SSW, distribuindose numa área mais larga na direção ENE-WSW, coincidindo com a orientação das anomalias aeromagnetométricas observada por
Hoff (2002). Nas imagens dos canais urânio e tório (Figuras 3 e 4 , respectivamente), as áreas de alta intensidade podem corresponder a corpos graníticos com dimensões da ordem de uma dezena de quilômetros ou mais. 0 maior destes corpos parece estar associado à faixa NNE-SSW de intensidade média/alta observada 
no canal potássio (Figura 5). Configura-se, assim, que 0 batólito da Suíte Pedras Grandes é aparentemente interrompido no limite dos domínios sul e norte.

Os domínios norte e sul parecem constituídos por associações de rochas distintas e terem diferentes estruturações. Ressalta-se que o limite entre os domínios coincide com a mais importante das faixas de lineamentos de direção ENE-WSW FSRL e com importantes padrões das anomalias aeromagnetométricas (Hoff et al., 2002).

\section{Alteração Hidrotermal}

No domínio sul do DFSC, observa-se com clareza a existência de zonações regionais nos canais urânio e tório. Os limites das zonas de maior intensidade de cada um destes canais não coincidem com os limites da área de ocorrência da Suíte Pedras Grandes. Além da zona central, esta área anômala é formada por zonas periféricas de intensidade média e, em diversos locais, áreas externas a estas zonas. 0 maciço Pedras Grandes apresenta uma zonação em urânio e tório e a ampliação da área de maior intensidade do Fator $\mathrm{F}$, em relaçã̃o às áreas de maior intensidade dos canais urânio e tório fornece a extensão e a intensidade da alteração hidrotermal que afeta o Maciço Pedras Grandes.

Sallet (1988) e Bastos Neto (1990) demonstraram que as alterações regionais afetam tanto 0 Granito Pedras Grandes como o Tabuleiro (que segundo Silva \& Leites (2000) correspondem aos Granitos Imaruí-Capivari e Jaguaruna), mas com intensidades e paragêneses distintas. Segundo Bastos Neto (op. cit.), a alteração hidrotermal foi bem mais intensa no Granito Tabuleiro, mais especialmente durante 0 estágio da mica branca. As ocorrências de molibdenita no Granito Jaguaruna são ligadas a este estágio de alteração hidrotermal, sendo coerentes com a presença de valores máximos do Fator $F$ nas ocorrências do Granito Jaguaruna adjacentes à planície costeira e demonstram a maior intensidade das transformações nas rochas mais finas, mais próximas à borda do maciço.

No domínio norte, a presença de alteração hidrotermal mais intensa é restrita ao entorno do Maciço Alcalino de Anitápolis, podendo estar relacionada ao magmatismo alcalino. Neste domínio, destaca-se a faixa de direção NNE-SSW onde os valores de Fator F destacam-se em relação a um background muito baixo.

\section{CONCLUSÕES}

Os produtos do processamento dos dados aerogamaespectrométricos do DFSC se mostraram uma excelente ferramenta para mapear a distribuição alteração hidrotermal regional nos gra- nitóides, definida pelo aumento relativo do potássio em relação ao urânio e tório e permitindo a definição de áreas mais favoráveis para a prospecção de fluorita no distrito.

Quando apoiada pelo conhecimento geológico da área e pelo controle da mineralização, a interpretação da imagem do fator $F$ é bastante útil para delimitar um zoneamento da alteração hidrotermal, mapeando áreas mais favoráveis à prospecção de fluorita.

0 Maciço Pedras Grandes, que antes tinha de dimensões extrapolando os limites do DFSC, ficou reduzido a partir deste estudo. E a concepção que enquadrava 0 DFSC dentro de um batólito homogêneo, não possibilitava visualizar um padrão de distribuição para a mineralização que não fosse apenas associando-as aos lineamentos. No presente estudo, o Maciço Pedras Grandes é um corpo intrusivo de dimensões mais restritas, dentro de limites definidos, com uma zonação de fácies à qual se relaciona uma série de processos de alteração hidrotermal cuja distribuição era incompreensível diante das dimensões anteriormente postuladas para o corpo granítico.

Esta nova interpretação para o Maciço Pedras Grandes permite reconhecer o padrão regional de distribuição dos depósitos de fluorita como predominantemente associados às bordas e às zonas periféricas ao maciço. Toda esta borda representa uma área de alta prospectabilidade, caracterizando um novo guia prospectivo: a relação espacial com a rocha fonte. Este padrão de distribuição reduz a prospectabilidade das partes mais interiores ao maciço. Porém, a localização do filão São Martinho (Bastos Neto, 1990) atesta que pode haver mineralização nestas partes.

Ao norte do Maciço Pedras Grandes, a delimitação de áreas mais prospectáveis fica condicionada à identificação de corpos graníticos Imaruí-Capivari/Jaguaruna, sendo possível que as importantes estruturas N-S e NE-SW existentes nesta região controlem intrusões graníticas como descrito por Flores (1998) na Zona de Cisalhamento Rio dos Bugres - ZCRB.

A distribuição dos depósitos (e subdistritos) de fluorita ao longo dos lineamentos obedece a um primeiro critério, que é a localização em relação à rocha fonte. Num segundo critério, pode ter sido influenciada por uma compartimentação imposta pelas grandes estruturas ENE-WSW e WNW-ESE. As primeiras, como suposto por Bastos Neto (1990) podem ter relações com as zonas de inflexão das estruturas que compõem os lineamentos $\mathrm{N}$ $S$ a NNE-SSW, assim como podem ter, em épocas posteriores à mineralização, controlado movimentações verticais de blocos responsáveis pela erosão de filões. As estruturas WNW-ESE podem ter exercido um papel fundamental no deslocamento dos fluidos hidrotermais e devem ser cuidadosamente consideradas na prospecção ao longo dos lineamentos mineralizados. 


\section{AGRADECIMENTOS}

Os autores agradecem à CPRM pelo fornecimento dos dados aerogeofísicos. Ao engenheiro de minas Altair Flamarion Klippel e ao geólogo Clóvis Norberto Savi (Grupo Votorantim), pelo apoio nos trabalhos de campo.

\section{REFERÊNCIAS}

BASTOS NETO AC. 1990. Le district a fluorine de Santa Catarina (Brésil): mineralizations e alterations hydrothermales dans lens cadre geodynamique. Orleans, 420pp. Thèse de doctorat en metallogenie. Université de Orleans.

BASTOS NETO AC, TOURAY JC, CHARVET JP \& DARDENNE MA. 1991. Tectonic setting of vein deposits in the Santa Catarina fluorite district (S. Brazil). In Pagel M. \& Leroy JL. Source, Transport and Deposition of Metals., eds. Balkema Rotterdam, p. 423-425.

BLAKELY RJ. 1996. Potential Theory on Gravity and Magnetic Applications. Cambridge Univ. Press. 440 pp.

CPRM - Companhia de Pesquisas de Recursos Minerais. 1994. Catálogo geral de produtos e serviços. Geologia. Levantamentos Aerogeofísicos. Base de dados AERO. $2^{\mathrm{a}}$ ed. Rio de Janeiro: Diretoria de Geologia e Recursos Hídricos, 367pp.

EFIMOV AV. 1975. Multiplikativnyi pokazatel dlja videlenija endogennych rud po aerogamma-spektrometrceskim dannym. In: Metody rudnoj geofisiki, edited by: Maucno-proizvodstevennoje objedinenie "Geofizica" Leningrad.

FLORES JAA. 1998. Mineralogia e Geoquímica das alterações metassomáticas e hidrotermais das rochas encaixantes da mineralização de fluorita da mina Rio dos bugres, Santa Catarina, Brasil. Porto Alegre, 245p. Tese de doutoramento, Instituto de Geociências, UFRGS.

FRAGOSO-CESAR ARS. 1980. 0 Cráton do Rio de La Plata e o Cinturão Dom Feliciano no Escudo Uruguaio-Sul-Riograndense. In: Congresso Brasileiro de Geologia, 31, Balneário Camboriú, SBG. Anais, 5: 28792892.

GEOSOFT. 1997. OASIS MontajTM Data Processing and analisys (DPA) System. V 4.2 Geosoft Inc., Toronto, Canadá.

HOFF R. 2002. Integração de dados geológicos, de sensoriamento remoto, espectrorradiométricos e geofísicos aplicada à prospecção de depósitos filoneanos de fluorita hidrotermal no Sudeste de Santa Catarina. Porto Alegre, 235p. Tese de doutoramento, Instituto de Geociências, UFRGS.

HOFF R, BASTOS NETO AC \& ROLIM SBA. 2002. Contribuição do EStudo Aeromagnetométrico e de Imagens Orbitais (TM LANDSAT 5) ao Conhecimento do Arcabouço Geológico do Distrito Fluorítico de Santa Catarina (Brasil) e suas Implicações para a Prospecção de Fluorita. Pesquisas em Geociências, 29 (2): 37-52.

MINTY BRS. 1991. Simple micro-leveling for aeromagnetic data. Exploration Geophysics, 22: 591-592.

MORGENTHAL A \& KIRCHNER CA. 1983. Síntese do mapa previsional do distrito de fluorita de Santa Catarina. In: Simpósio Sul-Brasileiro de Geologia, 1. Porto Alegre, SBG. Atas: 294-306.

ROLIM SBA. 2001. Resposta geofísica dos depósitos de ouro da porção central do Quadrilátero Ferrífero, MG. Tese de Doutoramento, Instituto de Geociências, UNICAMP. Campinas, 290p.

SALLET R. 1988. Étude pétrologique et métallogénique d'un secteur du District à Fluorine de Santa Catarina, Brésil. Les granitoïds précambriens monzonitiques source probable de la fluorine filonienne post-jurassique. Thèse de Doctorat. Université de Paris VI, 233p.

SALLET R, MORITZ R \& FONTIGNIE D. 2000. Fluorite 87Sr/86 Sr and REE constraints on fluid-melt relations, crystallization time span and bulk DSr of evolved high-silica granites. Tabuleiro granites, Santa Catarina, Brazil. Chemical Geology, 164: 81-92.

SILVA MAS \& LEITES SR. 2000. Programa Levantamentos Geológicos Básicos do Brasil. Criciúma, Folha SH.22-X-B. Estado de Santa Catarina. Escala 1:250000. Organizadores. CPRM, Brasília. CD-ROM.

TEIXEIRA CAS. 1969. Relatório de datações geocronológicas do Projeto Básico da Região Leste e do Projeto Específico da Fluorita. Porto Alegre, DNPM. Inédito, 39p.

VASCONCELOS RM, METELO MS, MOTA AC \& GOMES RD. 1990. Geofísica em levantamentos geológicos. Relatório DIGEOF/CPRM. Rio de Janeiro.

ZANINI LFP, BRANCO PM, CAMOZZATO E \& RAMGRAB GE. 1997. Programa Levantamentos Geológicos Básicos do Brasil. Folha Florianópolis (SG 22-2-D-V) e Lagoa (SG 22-2-D-VI) (1:100.000). CPRM, Brasília, $259 p$. 


\section{NOTAS SOBRE OS AUTORES}

Rosemary Hoff. Graduada em Geologia pela UNISINOS (1984), Especialista em Gerenciamento Ambiental pela UNISINOS (1990), Mestre em Sensoriamento Remoto pela UFRGS (1996) e Doutora em Ciências pela UFRGS (2002). Coordenadora do Laboratório de Sensoriamento Remoto e Espectrorradiometria (SUREG - PA) do Serviço Geológico do Brasil - CPRM.

Sílvia Beatriz Alves Rolim. Graduada em Geologia pela UFRGS (1988), Mestre em Sensoriamento Remoto pelo INPE (1992) e Doutora em Ciências pela UNICAMP (2001). Professora adjunta do Departamento de Geodésia do Instituto de Geociências da UFRGS. Professora do Curso de Pós-Graduação em Sensoriamento Remoto do CEPSRM/UFRGS

Artur Cezar Bastos Neto. Graduado em Geologia pela UFRJ (1977), Mestre em Geociências pela UFRJ (1980) e Doutor na Université de Orleans (1990). Professor Titular do Departamento de Mineralogia e Petrologia do Instituto de Geociências UFRGS. Professor do CPGq/UFRGS. 